\title{
TRABalHo DE CAMPo PARA ANÁlISE LINGUísticA EM SEmÂntica Formal
}

\author{
Fieldwork for linguistic analysis \\ in Formal Semantics
}

\author{
Luciana Sanchez-Mendes *
}

\section{RESUMO}

O objetivo deste artigo é descrever e justificar a metodologia utilizada nos trabalhos de campo para coleta de dados linguísticos para análise em Semântica Formal. O trabalho procura esclarecer algumas questões teóricas, práticas e éticas envolvidas em um trabalho como esse. Sua tese principal é a de que o paradigma teórico determina a metodologia e o tipo de corpus coletado. Em Semântica Formal, especificamente, a metodologia defendida é a elicitação controlada.

Palavras-chave: metodologia; trabalho de campo; Semântica Formal.

* Doutora pela Universidade de São Paulo e pela Université Paris 8. 


\begin{abstract}
The aim of this paper is to describe and to justify the fieldwork methodology to collect linguistic data for an analysis in Formal Semantics. The article seeks to clarify some theoretical, practical and ethical issues. Its main claim is that the theoretical paradigm determines the methodology and the kind of collected corpus. On Formal Semantics specifically we defend the controlled elicitation as the best methodology.
\end{abstract}

Keywords: methodology; fieldwork; Formal Semantics.

\title{
1. INTRODUÇÃo
}

O objetivo deste artigo é descrever a metodologia utilizada nos trabalhos de campo para coleta de dados linguísticos para análise em Semântica Formal. O trabalho procura esclarecer algumas questões teóricas, práticas e éticas envolvidas em um trabalho como esse. A título de exemplo, trataremos da coleta de dados da língua Karitiana para uma análise da modificação de grau em sentenças como (1) abaixo ${ }^{1}$ :

$$
\begin{array}{ll}
\text { João } \varnothing \text {-na-pytim'adn- } \varnothing & \text { pitat }^{2} . \\
\text { João } 3 \text {-DEcL-trabalhar-NFut } & \text { muito } \\
\text { 'O João trabalhou muito' } &
\end{array}
$$

Embora os exemplos utilizados sejam muitas vezes retirados dessa pesquisa específica, o objetivo principal deste artigo é descrever de maneira geral o processo de coleta de dados linguísticos para análise em Semântica Formal. Ele pode, portanto, ser útil tanto para pesquisadores envolvidos na análise de línguas pouco estudadas, como as línguas indígenas brasileiras, quanto para aqueles que investigam línguas como o português.

1 Os dados da língua Karitiana são apresentados da seguinte forma: primeira linha: transcrição ortográfica da sentença em Karitiana com a separação dos morfemas; segunda linha: glosa de cada morfema da sentença; terceira linha: tradução para a língua portuguesa. A tradução é apenas aproximativa, como ficará claro ao longo da discussão do texto.

$2 \quad$ As abreviações usadas para os morfemas são as seguintes: 3 = concordância de terceira pessoa; $\mathrm{DECL}=$ modo declarativo; NFUT $=$ tempo não futuro. 
A tese defendida é de que a escolha do quadro teórico de uma pesquisa linguística determina diretamente a metodologia utilizada para coletar os seus dados. Em Semântica Formal, especificamente, defendemos a metodologia de Elicitação Controlada, conforme proposta por Mattewson (2004). Este texto procura justificar esse modelo, que ainda é controverso. Embora haja um considerável número de trabalhos publicados dedicados à pesquisa de campo, esse ainda é um assunto que suscita debate e discordância entre linguistas ${ }^{3}$.

A próxima seção descreve brevemente os objetivos de uma pesquisa inserida no paradigma teórico da Semântica Formal. Em seguida, a Seção 3 discute de modo amplo o que é metodologia de trabalho de campo em linguística. Muitas afirmações são feitas de forma genérica. A Seção 4, no entanto, apresenta concretamente de que modo essas questões tomam forma quando se trata de um caso específico, como o dos quantificadores adverbiais da língua Karitiana com o paradigma teórico da Semântica Formal. A Seção 5 discute, por fim, algumas questões éticas envolvidas em um trabalho como este.

\section{SEMÂNTICA Formal}

O objetivo desta seção é descrever brevemente o quadro teórico da Semântica Formal. Mais especificamente, abordaremos as características da Semântica Formal tal qual é definida em Heim e Kratzer (1998). Outras abordagens possíveis para a Semântica Formal não serão discutidas.

Semântica, em seu sentido geral, é o estudo do significado. Diferentes modos de descrever o que é significado moldam diferentes tipos de semânticas. Em primeiro lugar, é preciso deixar claro que o objeto linguístico de interesse da Semântica Formal (SF) é a sentença ${ }^{4}$. A SF não busca entender aspectos do significado de palavra isoladas, como a Semântica Lexical, nem o significado de unidades maiores que a sentença, como a Semântica Discursiva ${ }^{5}$.

A Semântica Formal descreve o significado das sentenças das línguas naturais como as suas condições de verdade. Saber o significado de

3 Ver, por exemplo, Crowley (2007), Newman e Ratliff (2001), e Chelliah e de Reuse (2011). a sentença também é importante para a análise em Semântica Formal. No entanto, o interesse está na contribuição do significado desses itens para as condições de verdade da sentença.

$5 \quad$ Semântica Lexical, Semântica Formal e Semântica Discursiva não esgotam os tipos de semânticas existentes. Ver Pires de Oliveira (1999) para uma descrição mais completa dos estudos do significado. 
uma sentença é saber quais as condições que permitem que essa sentença seja verdadeira. Assim, a Semântica Formal é uma teoria do significado que emparelha sentenças com suas condições de verdade em um esquema como (2), abaixo (TARSKI, 1935).

$$
\text { A sentença “_ _ é verdadeira se, e somente se, }
$$

$\mathrm{Na}$ fórmula em (2), o que aparece entre aspas, no primeiro espaço, é a sentença da língua objeto que está sendo investigada. No segundo espaço, depois de $s e$, e somente se, aparece a descrição das condições de verdade da sentença. Essa descrição é feita por meio de uma metalinguagem, que é a língua utilizada para se falar da língua objeto. A metalinguagem utilizada pela teoria poderia ser qualquer uma, como o inglês ou o português. No entanto, a fim de explicitar fenômenos linguísticos bastante precisos, a teoria semântica utiliza uma metalinguagem enriquecida com um vocabulário técnico nas suas representações.

O objetivo final de uma análise semântica é explicitar, por meio de uma forma lógica elaborada na metalinguagem, as condições de verdade, e portanto, o significado de uma sentença de uma língua natural ${ }^{6}$. Esse princípio é baseado na proposta de Richard Montague (1973), uma das ideias centrais na origem da Semântica Formal, de que fragmentos das línguas naturais, como o inglês, poderiam ser tratados como linguagens formais.

Mas o pareamento entre sentenças e suas respectivas condições de verdade é apenas o resultado da análise. O trabalho do linguista está em analisar como o sistema semântico produziu esse significado. Para isso, ele precisa entender como o encadeamento de palavras que forma a sentença pode ser computado para gerar as suas condições de verdade. É nesse sentido que se assume que a interpretação semântica é composicional. o significado de uma sentença depende do significado de suas partes e de sua estrutura sintática, ou seja, de como as suas partes estão organizadas. Assim, a SF procura investigar de que modo o significado de cada parte de uma sentença contribui para as suas condições de verdade. Os exemplos apresentados nesse artigo estão associados a uma pesquisa que tem como objetivo investigar qual a contribuição dos advérbios de quantificação para o significado das sentenças.

6 Uma vez que o interesse maior deste artigo é discutir sua metodologia, não vamos apresentar as formas lógicas elaborada na metalinguagem técnica, vamos apenas apresentar as condições de verdade descritas em língua portuguesa. 
Uma vez apresentado o quadro geral da Semântica Formal, a próxima seção discute de forma geral o que é trabalho de campo em linguística para, em seguida, aproximar as noções e discutir metodologias de trabalho de campo para uma pesquisa em Semântica Formal.

\section{O oue É Trabalho de Campo em Linguística?}

O trabalho de campo em Linguística, em seu sentido tradicional, envolveu, por muito tempo, um pesquisador vivendo na comunidade que falava a língua que se pretendia estudar. Pelo método de imersão, o linguista teria acesso à língua em seu contexto natural. Esse método foi o predominante desde os primeiros estudos das línguas indígenas americanas feitos por missionários no século XVI até o apogeu da tradição estruturalista americana.

Linguistas estruturalistas como Sapir e Bloomfield seguiram a tradição estruturalista de trabalho de campo segundo a qual a coleta de dados não se distingue da interação e da observação direta das comunidades estudadas. Nessa tradição, toda a linguística descritiva tinha origem em trabalhos de campo com interação com falantes nativos (CHELLIAH; DE REUSE, 2011). Esse é o modo de trabalho de campo reconhecido como legítimo e defendido por muitos linguistas como Everett (2001) e Aikhenvald (2007). Bowern (2008), por exemplo, define o trabalho de campo somente como aquele em que uma língua é estudada no lugar onde ela é falada pelos seus falantes.

Outros linguistas pós-estruturalistas reconhecem, no entanto, que é possível fazer trabalhos de campo com bastante sucesso por meio de coletas baseadas em entrevistas, sem a necessidade de o linguista se tornar um membro da comunidade que fala a língua estudada. Segundo Chelliah e de Reuse (2011), não há uma diferença qualitativa na coleta de dados nesses dois modos de trabalho. É possível fazer bons trabalhos de campo por meio de entrevistas e trabalhos de campo ineficientes em um ambiente de imersão na língua estudada. E vice-versa. Além disso, os autores chamam a atenção para o fato de que o trabalho de campo em linguística em ambientes não exóticos é muito mais comum do que parece quando se lê os textos sobre o assunto.

O linguista de campo não é mais aquela figura caricata do pesquisador que desbrava a selva em busca de dados linguísticos. Segundo Crowley (2007), por muito tempo os pesquisadores em linguística foram divididos em dois tipos: os linguistas pés-sujos, que fazem os trabalhos de campo, e que não possuem nenhuma sofisticação teórica; e os linguistas de poltrona, 
que fazem suas teorias baseadas em dados introspectivos e totalmente fora da realidade (termos do autor). Crowley (2007) afirma que essa dicotomia caricata não se sustenta mais. Os trabalhos recentes em linguística mostram que a chamada "Linguística Descritiva" necessita de uma teoria que a auxilie e que a dita "Linguística Teórica" não se sustenta sem um conjunto de dados.

Nesse sentido, é possível que o trabalho de campo se realize na comunidade dos falantes ou, ainda, em um outro ambiente, no qual os linguistas possam se encontrar com os falantes. Muitas vezes, por questões técnicas, a segunda possibilidade é a preferida. É o caso de trabalhos de campo em fonética e fonologia que envolvem gravações com o uso de equipamentos específicos que ficam na universidade. Embora esse não seja o caso da coleta de dados para análise em Semântica Formal, defendemos que o trabalho de campo pode ser realizado tanto na comunidade dos falantes da língua quanto em outros ambientes.

Logo, o termo trabalho de campo tem, atualmente, um sentido muito mais amplo do que tinha até meados dos anos 1950. Segundo Chelliah e de Reuse (2011), o trabalho de campo em linguística descritiva compreende tanto a coleta de dados por meio de interação com os falantes em situações de uso natural da língua quanto por meio de entrevistas. A próxima seção discutirá de que forma a teoria e a prática estão presentes na coleta de dados em pesquisa linguística.

\section{Teoria e Prática no Trabalho de Campo}

Há muitas formas de se coletar dados linguísticos, cada uma delas mais ou menos apropriada para um determinado tipo de investigação. Uma pesquisa que tenha como objetivo a investigação da fonologia de uma língua utiliza instrumentos e métodos que não são necessariamente adequados para uma investigação da sintaxe dessa língua. Um trabalho que pretenda investigar, por exemplo, os processos fonológicos do português brasileiro não pode reunir dados baseados apenas em textos escritos. Já um trabalho em sintaxe gerativa, que depende de evidências negativas (dados agramaticais), não pode ser feito com base apenas em dados espontâneos (CHOMSKY, 1961). Nesse sentido, no trabalho de campo a teoria e a prática não podem ser desvencilhadas.

Essa não é, no entanto, uma postura compartilhada por todos os pesquisadores sobre o assunto. Abbi (2001), por exemplo, afirma que a teoria amarra as mãos do linguista de campo (termo da autora) no sentido de que ela limita a autonomia do pesquisador direcionando-o a uma coleta de da- 
dos limitada. Bowern (2008), por outro lado, assume que teoria e descrição não são mutuamente exclusivas, e que a teoria é inerente à pesquisa. Não é possível fazer a descrição de uma língua sem a formulação de hipóteses sobre como ela funciona. Quando o pesquisador faz a descrição de uma língua, as escolhas dos dados e a metalinguagem das categorias revelam o emprego de uma teoria.

Bowern (2008) faz uma comparação interessante entre o trabalho do linguista de campo e o de Sherlock Holmes. O investigador muitas vezes pedia a seu companheiro Watson para fazer a descrição do cenário de um crime. Watson, inexperiente, tem problemas na tarefa porque não sabe exatamente o que o seu professor está pedindo. Holmes, nesse momento, intervém e chama a atenção no sentido de que só é possível executar a tarefa se você possui uma hipótese, algo para procurar. Segundo Bowern (2008), o trabalho de campo envolve descobertas por meio de perguntas, mas o pesquisador precisa saber quais perguntas fazer. A experiência do linguista e o quadro teórico com o qual trabalha, seja ele de que tipo for, o ajudam a determinar quais perguntas elaborar e a fazer predições passíveis de serem testadas.

Nesse sentido, defendemos que não há diferença qualitativa entre descrever e analisar. A pesquisa que é chamada de descritiva não é possível de ser executada sem uma teoria e a que é considerada teórica não pode se desenvolver sem o uso de um corpus. o procedimento de coleta de dados utilizado em uma pesquisa em Semântica Formal está fortemente ligado ao paradigma dessa teoria. Esta seção discutiu de modo genérico as características de trabalho de campo de linguística. Mais especificamente, a defesa de que teoria e prática estão intimamente ligadas nesse processo. A próxima subseção procura ilustrar essas afirmações com exemplos apresentados de forma detalhada.

\subsection{Semântica Formal e Elicitação Controlada}

Esta seção apresenta a metodologia utilizada para coleta dos dados linguísticos adequados para a sua investigação nos moldes da Semântica Formal. O objetivo é mostrar que a elicitação controlada é o modo mais apropriado para a coleta de sentenças acompanhadas de suas respectivas condições de verdade, o objeto de estudo do paradigma utilizado. O protocolo seguido é basicamente o que se encontra descrito em Matthewson (2004) e vem sendo empregado amplamente nos trabalhos de campo para coleta de dados linguísticos nesse modelo teórico. Conforme discutido anteriormente, o objetivo da Semântica Formal é investigar qual a contribuição de 
cada expressão linguística para as condições de verdade associadas a uma sentença (que revelam, segundo a teoria, o seu significado). Logo, a coleta de dados para pesquisa nesse paradigma teórico deve conduzir a sentenças acompanhadas de suas respectivas condições de verdade.

Um possível primeiro passo de aproximação aos dados de uma língua desconhecida é a consulta do acervo de seus dados espontâneos, escritos ou não. Entretanto, nem sempre a língua que se quer investigar possui um acervo desse tipo. Além disso, esse passo é apenas uma aproximação aos dados da língua. É impossível coletar as informações necessárias para uma investigação sobre as condições de verdade das sentenças apenas por meio do discurso espontâneo ou de textos. Os dados que podem ser obtidos pelo uso exclusivo desse método quase sempre são insuficientes, pois não fornecem informações mais sutis ou dependentes do contexto, as quais são cruciais para o estudo do significado das sentenças. A sentença em (3), por exemplo, foi retirada de uma narrativa oral em Karitiana traduzida para $o$ português (MALOSSO, 2003).

a. Mynda, y'ete'et, ipibmam 'in tyym ikytop, iohynam pitat yj'a tykiri taka'a okot bypiitap tairisooty. Ty'ooman 'ej se'yp am'a tykiri. 'Sem pressa, a gente faz a quantidade de chicha, porque quando a gente faz muita chicha, acontece morte próxima.'

b. Taso tapyot iataki pitat tyym, isoko'im tyym, kyj, i'a tykit imbodn. 'Todos fazem o moquém, amarram sem arrebentar o cipó. Se arrebentar, não é bom.'

Suponha que queremos usar essas sentenças para estudar o modificador de grau pitat na língua. Pode-se observar que é impossível retirar informações acerca de seus usos possíveis e quais as condições de verdade das sentenças em que esse advérbio aparece a partir de sentenças como essas. Quanto à distribuição, é impossível retirar de dados como em (3) uma generalização sobre as possibilidade de uso de pitat. Para isso, são necessárias evidências negativas. É de extrema importância saber quais sentenças não podem ser produzidas em uma língua. Para a investigação do significado, a deficiência desse tipo de dado se torna ainda mais dramática. Podemos ver que o que temos em (3) é apenas uma tradução adequada para o contexto em que pitat ocorreu nessa narrativa. Não conseguimos obter informações de outras situações em que essas sentenças poderiam ser usadas, ou ainda 
saber em que contextos elas não poderiam ser utilizadas adequadamente. Esse tipo de informação é essencial e não aparece nos corpora de discurso espontâneo.

Nesse sentido, o trabalho de campo com elicitação controlada é de suma importância para uma pesquisa como essa ${ }^{7}$. A elicitação controlada é um método de coleta de dados baseado em entrevistas que possui, basicamente, duas etapas: traduções e julgamentos de contextos. Nas duas etapas, Matthewson (2004) defende o uso de uma metalíngua como instrumento, uma língua que não seja a língua que está sendo investigada e que seja conhecida pelo pesquisador e pelo consultor ${ }^{8}$. A metalíngua utilizada em nossas pesquisas com os Karitiana é o português brasileiro.

A primeira etapa da elicitação envolve a coleta de traduções, que representam ferramentas importantes para o trabalho de campo. No entanto, elas devem ser utilizadas como pistas e não como resultados, constituindo a menor parte do trabalho de campo. A autora defende que sempre sejam pedidas traduções de sentenças completas e nunca de palavras ou sintagmas menores que uma sentença. Isso porque não é fácil, para o consultor, isolar a sequência que é relevante em sua língua ou, muitas vezes, a tradução pode não ser possível porque uma sequência de três palavras numa língua pode ter apenas uma em uma outra.

O exemplo (4a) ilustra esse fato. Em Karitiana, a palavra aniki pode ser traduzida para o português como 'estar com frio'. (4b) traz um exemplo em inglês em que ocorre o contrário: duas palavras give up traduzida para uma ('desistir'). Veja que alguém que tentasse traduzir give up para o português traduzindo palavra a palavra chegaria a algo sem sentido, como 'dar acima'.
a. aniki
(Karitiana)
'estar com frio'
(Landin 1983)
b. give up
(Inglês)
'desistir’

$7 \quad$ No entanto, nem todos os linguistas aceitam que a elicitação controlada seja um bom método de coleta de dados. Entre os autores que rejeitam o tipo de elicitação utilizada nesta pesquisa e descrita nesta seção estão Schutze (1996), Dimmendaal (2001) e Mithun (2001).

8 Bowern (2008) prefere o termo consultor à informante, pois defende que consultor tem a conotação de um especialista que é consultado sobre um tópico específico. Estamos seguindo a sua sugestão no uso do termo. 
Para se fazer traduções de sentenças, segundo Matthewson (2004), deve-se partir de cenários descritos na metalíngua que descrevem o contexto no qual está inserida a sentença que se quer traduzir, para depois o pesquisador falar a sentença. Se a sentença vier antes, ela pode induzir o consultor a contextos diferentes daquele que o pesquisador quer elicitar. A autora afirma que a influência da metalíngua sobre o consultor é desprezível, uma vez que ela exerce tanta influência quanto exerceria a língua objeto se o contexto fosse criado nessa língua. As sentenças de que se parte na metalíngua devem ser gramaticais e deve-se assumir que as sentenças obtidas na língua objeto são também gramaticais.

Por exemplo, para se coletar a tradução da sentença em Karitiana para "O ovo caiu", deve-se proceder da seguinte forma:

(5) O cenário é um ninho em cima de uma árvore. Eu quero dizer que o ovo que estava no ninho caiu; como eu falo em Karitiana: "O ovo caiu"?

No entanto, nem todas as pistas semânticas de que se necessita aparecem diretamente nas traduções. Quando se pede, por exemplo, a tradução de uma sentença em português para o Karitiana, a sentença obtida pode não corresponder exatamente à sentença em português. Pode acontecer de a sentença em Karitiana poder ser usada em situações em que a sentença em português não é apropriada e vice-versa, ou seja, as sentenças podem não ter as mesmas condições de verdade. Há falta de correspondência entre o Karitiana e o português, por exemplo, na tradução dos sintagmas nominais formados por nomes comuns. Em Karitiana, os nomes comuns são sempre nus, e nunca aparecem com determinantes ou quantificadores nominais (MÜLLER; STORTO; COUTINHO-SILVA, 2006). Dessa forma, o exemplo criado em (5) com a sentença em português "O ovo caiu" terá no máximo uma tradução correspondente a "Ovo caiu" em Karitiana, conforme demonstrado em (6), abaixo.

$$
\begin{aligned}
& \text { Sypi } \varnothing \text {-naka-'ot- } \varnothing . \\
& \text { ovo } 3 \text {-DECL-cair-NFUT } \\
& \text { 'Ovo caiu' }
\end{aligned}
$$

Um outro exemplo da falta de correspondência entre as sentenças do Karitiana e do português está ilustrado em (7). Ao se pedir em Karitiana uma tradução para $O$ Inácio esperou muito, obteve-se a seguinte sentença: 


$\begin{array}{lll}\text { Inácio } & \varnothing \text {-naka-kydn- } \varnothing & \text { kandat. } \\ \text { Inácio } & 3 \text {-DEcL-esperar-NFut } & \text { muitas.vezes } \\ \text { 'O Inácio esperou muito' } & \end{array}$

Em Karitiana, essa sentença só pode ser usada para cenários em que o Inácio esperou muitas vezes. Ela não é apropriada para descrever um cenário em que o Inácio esperou uma vez por muito tempo. Já a sentença em português "O Inácio esperou muito" é apropriada nesse contexto. Uma vez que a diferença entre iteração e duração é extremamente importante para o estudo dos advérbios de quantificação (cf. DOETJES, 2007), o método de tradução apenas não é suficiente.

Essa impossibilidade de tradução um para um é descrita em Quine (1960) como a indeterminação da tradução radical. A tradução completa de uma língua para outra é impossível, uma vez que cada sistema linguístico tem sistemas de significados distintos. Esses sistemas não podem ser alcançados ostensivamente, ou seja, não é possível simplesmente apontar no mundo uma referência na tentativa de reproduzir o significado de uma expressão, uma vez que significado e referência não são a mesma coisa. Segundo Frege (1892), o significados dos termos linguísticos pode ser dividido em sentido e referência. Grosso modo, a referência é o objeto ao qual o termo se refere, enquanto que o sentido diz respeito ao modo como o termo faz a referência. A despeito dessa diferença, uma das formas de se investigar o significado de um termo é por meio de sua referência. Os problemas decorrentes dessa tentativa são devido ao que ficou conhecido na literatura como a inescrutabilidade da referência. O exemplo de Quine (1960) é a palavra gavagai. Se um linguista estudando uma língua percebe que os falantes parecem utilizar a palavra gavagai nas mesmas situações em que utilizaríamos a palavra coelho em português, ele não pode assumir que gavagai e coelho se referem à mesma coisa. Em cada língua, as palavras podem agrupar conceitos distintos. No exemplo do Karitiana em (7), vimos que embora muito, do português, possa ser traduzido em alguns casos por kandat, do Karitiana, esse não é sempre o caso.

Desse modo, a segunda etapa da elicitação controlada sugerida por Matthewson (2004) é crucial para os trabalhos que investigam o significado. Trata-se da coleta de julgamentos do valor de verdade de sentenças em contextos particulares. O guia sugerido pela autora para a etapa dos julgamentos segue o modelo sugerido para as traduções: o pesquisador fala na metalíngua primeiramente o contexto no qual está inserida a sentença e, em seguida, a sentença na língua objeto. $O$ objetivo é checar a aceitabilidade da sentença no contexto sugerido. 
Na etapa de elicitação de julgamentos, o uso do contexto é fundamental. Mais até do que para as traduções. É impossível questionar quais os valores de verdade de uma sentença sem apresentação de um contexto. A relação da sentença com o contexto pode ser de dois tipos:

(8) a. Se um falante aceita a sentença S em um contexto C, S é verdadeira em C.

b. Se uma sentença S é falsa em um contexto $\mathrm{C}$, o falante vai rejeitar S em C.

Nota-se que, se o consultor rejeita uma sentença em um contexto, isso não é suficiente para se assumir que a sentença é falsa. Pode acontecer de a sentença ser rejeitada por ser infeliz nesse contexto. A infelicidade de uma sentença pode estar associada a falhas de pressuposição ou inverossimilhanças pragmáticas. Um fato que surgiu da coleta com o Karitiana ilustra um caso de inverossimilhança pragmática. Na coleta de dados da língua, solicitamos o julgamento da sentença em (9a). A sentença foi rejeitada sem nenhum motivo ligado a sua gramaticalidade ou a suas condições de verdade. $\mathrm{O}$ que ocorre nesse caso é uma impossibilidade ou improbabilidade pragmática: não são os homens que buscam água na aldeia Karitiana, mas as mulheres. Nesse caso, foi elaborada uma sentença infeliz. Nesse sentindo, a sentença foi substituída pela versão em (9b).

$\begin{array}{llll}\text { (9) a. } & \text { Taso } \quad \varnothing \text {-naka-ot- } \varnothing & \text { ese. } \\ & \text { homem } \quad \text { 3-DEcL-pegar-nfut } & \text { água } \\ & \text { 'Os homens pegaram água. }{ }^{9} & \\ \text { b. } & \text { Jonso } \quad \text { Ø-naka-ot- } \varnothing & \text { ese. } \\ & \text { mulher } \quad \text { 3-DEcL-pegar-NFut } & \text { água }\end{array}$

'As mulheres pegaram água.'

No caso específico do estudo dos modificadores de grau em Karitiana em dados como em (1), repetido abaixo em (10), o procedimento para a coleta dos julgamentos de verdade está descrito em (11):

9 Optamos por traduzir as sentenças com artigo desfinido porque o plural nu em português não é natural na posição de sujeito dessas sentenças. No entanto, conforme discutido anteriormente, a sentença em Karitiana não tem informaççoes quanto à definitude, uma vez que não apresenta artigos de nenhum tipo. 


$\begin{array}{ll}\text { João } \varnothing \text {-na-pytim'adn- } \varnothing & \text { pitat. } \quad=(1) \\ \text { João } 3 \text {-DECL-trabalhar-NFut } & \text { muito }\end{array}$

(11) a. Em um contexto em que o João trabalhou muitas vezes esta semana ou este mês, eu posso usar a sentença "João napytim'adn pitat"?

b. Em um contexto em que o João trabalhou uma vez por muito tempo esta semana, eu posso usar a sentença "João napytim'adn pitat"?

c. Em um contexto em que o João trabalhou uma vez por pouco tempo, mas bastante intensamente esta semana, eu posso usar a sentença "João napytim'adn pitat"?

Os contextos usados na elicitação controlada desse dado foram criados levando-se em conta a teoria na qual ele está embasado. Para o estudo dos quantificadores adverbiais de grau, é crucial a diferença entre iteratividade, duração e intensidade (DOETJES, 2007), representados em (11a), (11b) e (11c) respectivamente. Vemos, portanto, que o quadro teórico adotado é absolutamente indispensável na composição do corpus de uma pesquisa como esta. A teoria não só organiza e analisa os dados, mas determina o tipo de corpus a ser coletado, uma vez que ela é crucial para a escolha dos dados e contextos elicitados.

Esta seção descreveu de que modo é feita a elicitação controlada, uma ferramenta metodológica indispensável para o trabalho de campo em Semântica Formal. A próxima seção trata de algumas questões éticas envolvidas nos trabalhos de campo em linguística.

\section{5. ÉTICA}

Esta seção pretende discutir brevemente a questão ética dos trabalhos de campo em linguística. Uma vez que se trata de uma prática que envolve seres humanos, ela suscita uma discussão a respeito de problemas éticos ${ }^{10}$. A questão ética é uma questão muito complexa que envolve muitas 
esferas, inclusive filosóficas (cf. RICE, 2012). O que se pretende fazer nesta seção não é discutir profundamente a questão, mas apenas descrever e justificar o modo pelo qual essas questões estão sendo encaradas em nossas pesquisas.

Segundo Bowern (2008), há dois tipos de questões éticas com as quais o linguista de campo tem que lidar. A primeira delas refere-se ao campo legal, associado ao comité de ética da Universidade em que se realiza a pesquisa ou às suas agências de fomento. O segundo tipo está associado ao comportamento ético do linguista em relação à comunidade da língua estudada.

Quanto à primeira esfera, a literatura sobre os trabalhos de campo em linguística falam muito pouco sobre a questão legal. Pouco se diz sobre como os órgãos gestores avaliam as pesquisas em linguística de campo. Nos Estados Unidos, a Linguistic Society of America possui uma Declaração de Ética para conduzir trabalhos de campo com coleta de dados linguísticos. No Brasil, no entanto, não há nada semelhante publicado pela Abralin (Associação Brasileira de Linguística). As agências de fomento brasileiras como o CNPq - Conselho Nacional de Desenvolvimento Científico e Tecnológico apresentam diretrizes baseadas na Comissão Nacional de Ética em Pesquisa (CONEP) criada pela Resolução do CNS 196/96, que está diretamente ligada ao Conselho Nacional de Saúde (CNS). Ou seja, essas diretrizes não estão adaptadas para avaliar projetos de pesquisa em linguística. Nas diretrizes do CNPq, encontra-se ainda referência à FUNAI - Fundação Nacional do Índio - quanto à permanência e trânsito em áreas indígenas, ainda assim pouco específica para o caso de pesquisadores linguistas. Nas universidades, as pesquisas contam com avaliações de Comitês de Ética em Pesquisa em cada instituto. No entanto, não é comum encontrar um Comitê de Ética em um instituto de Ciências Humanas. Eles estão quase sempre associados aos institutos de Ciências Biológicas.

A segunda esfera ética, que diz respeito ao comportamento ético do linguista em relação à comunidade da língua estudada, também é bastante complexa, pois o comportamento ético pode depender da cultura ${ }^{11}$. Essa não é, no entanto, uma desculpa para ignorar as questões éticas. É possível seguir uma pesquisa ética a partir do princípio geral de maximizar os benefícios e minimizar os riscos para as partes envolvidas (pesquisadores e falantes) (RICE, 2012; BOWERN, 2008). 
Rice (2012) sugere que o primeiro passo seja a negociação. É preciso primeiramente explicar aos consultores o trabalho que se pretende fazer e $o$ que se pretende estudar. É preciso considerar que a comunidade espera algo do linguista e é essencial discutir como o trabalho pode ser realizado para que todos se beneficiem. Nesse ponto, é essencial conhecer o histórico dos trabalhos de linguistas na comunidade para compreender a percepção que os falantes têm do linguista de campo. Muitas vezes, o papel do linguista se confunde com o dos colonizadores, dos missionários ou dos agentes de saúde (CHELLIAH; DE REUSE, 2011). Além disso, Rice (2012) e Bowern (2008) chamam a atenção para o fato de que a negociação deve ser constante, pois é sempre possível haver mudanças nas decisões da comunidade, e elas devem ser sempre respeitadas.

Uma parte importante das negociações diz respeito ao modo de retribuição aos consultores pelo tempo dispensado no trabalho. Todos os trabalhos consultados sobre o assunto foram unânimes em afirmar que é preciso estabelecer alguma compensação aos consultores, que não precisa ser necessariamente em dinheiro - pode ser com algum tipo de benefício que auxilie os participantes e a sua comunidade. Se em dinheiro, o modo de pagamento deve ser adequado à comunidade e deve ser baseado no valor que é geralmente aceitável naquela cultura (RICE, 2012; BOWERN, 2008).

Rice (2012) afirma que estabelecer um meio e um valor de retribuição é demonstrar respeito à comunidade cuja língua é estudada. Bowern (2008) diz ainda que uma compensação apropriada pelo tempo dispensado formaliza a relação entre o pesquisador e o consultor e encoraja os envolvidos a trabalhar de modo sério, considerando a coleta de dados como um trabalho que precisa ser feito, e não um passatempo.

Esta seção mostrou brevemente algumas diretrizes para a condução ética do trabalho de campo em linguística.

\section{Conclusões}

Este artigo tratou de algumas questões envolvidas em trabalhos de campo para a coleta de dados linguísticos. Primeiramente, o trabalho desmistificou a figura do linguista de campo mostrando que a coleta de dados linguísticos não está associada necessariamente a ambientes exóticos. Além disso, a própria existência de um linguista de campo foi questionada. Uma vez que se defendeu que não há uma diferença significativa entre descrever e analisar, não faz sentido separar os linguistas entre pesquisadores teóricos e práticos. 
Por meio de exemplos retirados da pesquisa sobre quantificadores adverbiais em Karitiana, mostramos que o paradigma teórico no qual se insere uma pesquisa linguística é o que determina o protocolo de formação de seu corpus. A Semântica Formal, por exemplo, uma vez que trabalha associando sentenças a suas condições de verdade, motiva uma coleta de dados que leve em conta traduções de sentenças e julgamentos dos seus valores de verdade. O protocolo apresentado pode ser útil a linguistas que estão trabalhando com dados de línguas minoritárias ou mesmo aos que estão lidando com o português.

Por fim, foi apresentada uma reflexão sobre algumas questões éticas que estão necessariamente envolvidas em um trabalho com seres humanos. Os tópicos foram brevemente discutidos com base em negociação e renegociação, tema recorrente em todos os trabalhos consultados.

\section{REFERÊNCIAS}

ABBI, Anvita. A Manual of Linguistic Field Work and Indian Language Structures. Munique: Lincom Europa, 2001.

AIKHENVALD, Alexandra. Linguistic fieldwork: setting the scene. STUF - Sprachtypologie und Universalienforschung 60 (1), p. 3-11, 2007.

BOWERN, Claire. Linguistic Fieldwork: a Pratical Guide. Nova Iorque: Palgrave; MacMillan, 2008.

CHELLIAH, Shobhana L.; DE REUSE, Willem J. Handbook of Descriptive Linguistic Fieldwork. New York: Springer, 2011.

CHOMSKY, Noam. Some Methodological remarks on Generative Grammar. Word 17, p. 19-39, 1961.

CROWLEY, Terry. Field Linguistics: a Beginner's Guide. Oxford: Oxford University Press, 2007. DIMMENDAAL, Gerrit. Places and people: field sites and informants. In: NEWMAN, P.; RATLIFF, M. (eds.) Linguistics Fieldwork. Cambridge: Cambridge University Press, 2001. p. 55-75.

DOETJES, Jenny. Adverbs and quantification: degree versus frequency. Lingua 117, p. 685-720, 2007. 
EVERETT, Daniel L. Monolingual field research. In: NEWMAN, P.; RATLIFF, M. (eds.) Linguistics Fieldwork. Cambridge: Cambridge University Press, 2001. p. 166-188.

FREGE, Gottlob. Über Sinn und Bedeutung. Zeitschrift für Philosophie und philosophische Kritik 100, p. 25-50. 1892. Traduzido para o inglês como "On Sense and Reference". In: Translations from the Philosophical Writings of Gottlob Frege. Tradução de P. Geach e M. Black. Oxford: Blackwell, 1980.

HEIM, Irene; KRATZER, Angelika. Semantics in Generative Grammar. Oxford: Blackwell Publishers, 1998.

LANDIN, David. Dicionário e Léxico Karitiana/Português. Brasília: SIL, 1983.

MALOSSo, Maíra G. Núcleos Funcionais em Karitiana. Relatório de Pesquisa não Publicado. 2003.

MATTHEWSON, Lisa. On the Methodology of Semantic Fieldwork. International Journal of American Linguistics 70, p. 369-415, 2004.

MITHUM, Marianne. Who shapes the record: the speaker and the linguist. In: NEWMAN, P.; RATLIFF, M. (eds.) Linguistics Fieldwork. Cambridge: Cambridge University Press, 2001. p. 34-54.

MÜLLER, A.; STORTO, L.; COUTINHO-SILVA, T. Número e a Distinção Contável-Massivo em Karitiana. Revista da Abralin, v. 5, p. 185-213, 2006.

MONTAGUE, Richard. The Proper Treatment of Quantification in Ordinary English. In: HINTIKKA, J.; MORAVCSIK, J.; SUPPES, P. (eds.) Approachs to Natural Language. Dordrecht: Reidel, 1973. p. 221-242.

NEWMAN, Paul; RATLIFF, Martha. Linguistic Fieldwork. Cambridge: Cambridge University Press, 2001.

PIRES DE OLIVEIRA, R. Uma História de Delimitações Teóricas: Trinta Anos de Semântica no Brasil. D.E.L.T.A., vol. 15, 1999.

QUINE, Willard Van Orman. Word and object. Cambridge: MIT Press, 1960.

RICE, Keren. Ethical Issues in Linguistic Fieldwork. In: THIEBERGER, N. (ed.) The Oxford Handbook of Linguistics Fieldwork. Oxford: Oxford University Press, 2012.

SCHUTZE, Carson T. The Empirical Base of Linguistics: Grammaticality Judgements and Linguistics Methodology. Chicago: University of Chicago Press, 1996.

TARSKI, Alfred. Der Wahrheitsbegriff in den formalisierten Sprachen. Studia Philosophica 1, p. 261-405, 1935. Traduzido para o inglês como "The Concept of Truth in Formalized Languages". In: Logic, Semantics, Matematics: Papers from 1923 to 1938. Tradução de J. H. Woodger. Oxford: Oxford University Press, 1956.

Submetido em: 25/04/2014

Aceito em: 30/07/2014 